\title{
Learning from Teaching in Communities: The Role of Higher Education in Africa
}

\author{
Mr Zamo Hlela \\ Lecturer: Centre for Adult Education \\ University of KwaZulu Natal, Pietermaritzburg, South Africa \\ Hlelaz@ukzn.ac.za
}

\section{Doi:10.5901/mjss.2014.v5n8p364}

\section{Abstract}

This paper argues for the promotion of afrocentric, indigenous learning practices in higher education contexts. It explores the application and building of local knowledge through a pre-university level service learning course and concludes that universities need to make provision for such kinds of learning in order to widen their student clientele. The paper presents the outcomes of a programme of the University of KwaZulu-Natal and the Regional Psycho Social Support Initiative (REPSSI), where non-traditional learners from eight different African countries participated in a service-learning programme. Although it was not designed as a research study, the paper draws on empirical data in the form of learner reflective reports for its analysis. The University provided a situated, supported distance learning approach for 495 learners who were trained in the field of caring for and supporting vulnerable children in Africa through a service learning module.

Keywords: Afrocentric paradigm, African indigenous learning, Situated, Supported Distance learning

\section{Introduction}

This paper presents the outcomes of an 18 months long certificate programme of the University of KwaZulu-Natal (UKZN) and the Regional Psycho Social Support Initiative (REPSSI), that provided an access route for learners from eight different African countries into higher education. The learner reflective reports suggested that the programme had also enabled appropriation of indigenous learning practices which contributed to student satisfaction. The certificate programme is a cross disciplinary programme and an Africa wide community engagement initiative by UKZN.

The certificate programme is a programme whose intentions are to face up to the African challenges from within the continent by professionalizing lay workers, that is people who are already involved in caring for children in difficult circumstances. It is about the development of a competent and a critical practitioner who can provide better care and support for vulnerable children.

The certificate programme is designed to provide access to university learning where opportunities are severely limited. Most importantly it provides access to learning about the self. Furthermore these learners through servicelearning create fertile Afrocentric learning spaces not often experienced within the academy.

Borrowing from article title by Litke (2002) 'Do all students "get it"'? in this paper we are challenged to ask: Does academia get it? Does the university value and utilise learning in context that a programme such as this one provides for the generation of knowledge through African indigenous learning approaches. The paper starts by the certificate programme structure and approach, the theoretical perspective that draws on Afrocentrism and postcolonial literature and finally a research design. This includes findings on: 1) The nature of the service-learning projects undertaken by the learners in their various contexts; 2) The learnings reported by the learners; 3) The discourses of development that emerged; 4) The lessons learnt that speak to both policy and practice for widening participation in under-resourced countries and through the use of distance education.

\section{The Certificate Programme}

The Certificate Programme (Working with Children, Families and Communities affected by HIV \& AIDS, Conflict, Poverty and Displacement in Africa) is an 18 months Situated, Supported Distance learning programme offered in three different models in countries in Africa. It started in 2010 and is still running.

Model one of the programme delivery which this paper focuses on is defined as a delivery phase located and centralized at UKZN. This means that all aspects of delivery, assessment and learner support were undertaken by UKZN with strong support of a local agency. The critical factor of model one was to introduce the programme to the country stakeholders and benchmark the quality in all processes. Eight countries were involved in this phase these being 
Lesotho, Malawi, Namibia, Swaziland, Tanzania, Uganda, Zambia and Zimbabwe. When the model was implemented in March 2010, 543 learners commenced, 484 successfully completing; one failed with 68 withdrawing.

July 2010 was the commencement of Model 2. Two more countries were added on to the existing 8 making it a total of ten. The new countries were Mozambique and Kenya. Each institution in Model 2 was responsible for undertaking aspects of the academic, administrative and logistical coordination. 1062 learners commenced, 933 passed and 91 withdrew. The third and final phase 'Model 3' started in 2012. Nine countries are now participating. The purpose of model 3 is to see the institution accrediting and awarding the certificate and undertaking all elements of academic design and delivery.

The programme design is made up of six different modules located in different disciplines that would not normally work together or collaborate. Module one is titled 'Introduction to personal development' (Psychology), Module 2 'Introduction to Human Rights based approach' (Law), module 3 'Youth and development' (social work), module 4 'Care and support for children at risk' (Psychology), module 5 'Integrated Community development' (Community Development) and Module 6 - 'Service-learning' (Adult Education)

\subsection{The Certificate Programme and accreditation}

The programme is formally accredited by UKZN as a short course. In line with the UKZN quality assurance templates for short courses and approved by both Faculty Quality Committees and the Academic Affairs Board of the College of Humanities, the modules and assessment regime were developed. They are pitched at level 4 (South African Qualification Authority) or equivalent to the end of high school (ISCED level 3) or entry into tertiary study (ISCED level 4) according to the International Standard Classification of Education (ISCED 1997). In other words while the programme is not at undergraduate level, with its theoretical focus it might be argued that it is at tertiary level or functions as an 'access into higher education' programme.

\subsection{Entry requirement}

While the average year of schooling prior to acceptance on this programme was 12 years, or K12, the programme utilised a placement test as a tool to provide unqualified learners an equal opportunity to register into the programme.

A good understanding of who the possible learners were was critical. Most of the learners in the programme were likely to have been out of school for many years, work as volunteers, and have many other responsibilities. It is this understanding that informed how the delivery mode was to be developed, the Situated Supported Distance Learning (SSDL).

\subsection{The delivery mode}

The SSDL is supported by five equally important components. These are: (1) Learning materials developed by specialists in the area from within UKZN. At a local level learners are (2) supported by local mentors trained and supported by UKZN through mentor training and a mentor guide. Learners attend four organized and structured day long (3) contact sessions within the community. Each module has (4) two continuous assessments designed for facilitation of the (5) applied theory and practice component.

The success of the SSDL is reflected in the high retention and throughput rate. In this programme, in Model 1, 484 learners had successfully completed the programme, only 1 had failed and 68 had withdrawn, making an overall $87.5 \%$ throughput. In model 2, 1062 learners commenced and a total of 933 (87.9\% ) passed and completed.

\subsection{The learners}

All learners in the programme work with children mostly on a volunteer basis. In model one the average learner was 34 years old with the oldest being 75 and the youngest being 19 years old. $52 \%$ of the total number of learners were females, $41 \%$ being males and $7 \%$ unknown. While the average year of schooling prior to acceptance on this programme was 12 years the programme utilizes a tool to provided unqualified learners an equal opportunity to register in the programme. The placement test is a UKZN Senate approved tool developed at the Centre for Adult Education to assess learner's suitability for the programme and ability to cope with the demands of the programme. The test has three focal areas: the potential learners' experience working in the field, the ability for learners to comprehend English, the ability to express themselves in English and lastly basic mathematical literacy. In model 2 for example 348 learners out of 1062 did 
not meet the conventional entry requirements but successfully completed the programme.

\subsection{The service learning module}

The service-learning module is a credit bearing capstone module that challenged learners to engage in a meaningful and context relevant service activity. This module helps develop guided and supported reflection spaces on the engagement in the light of the theoretical input that learners would have covered in the previous five modules. This is achieved through an assessment regime that includes attendance (20\%), Journal entries (10\%), Assignment 1 (25\% marked at UKZN), Presentation (5\%) and Assignment 2 (40\% marked at UKZN).

The main purpose of assignment one was to ensure that learners had a realistic, achievable plan for their servicelearning project reflecting both service (do with) and learning (for both the learners and community). We wanted learners to have a positive learning experience where they contributed meaningfully to an identified community. The assignment attempts to ensure that most of the necessary steps were in place to ensure a successful learning experience. The assignment also requires learners to demonstrate:

- A good understanding of the context in which they would be working

- An awareness of the challenges they could face in this context and how they planned to deal with these

- A learning contact developed in collaboration with the host organisation

- A respectful attitude towards their community site

- Realistic goals for both their service and learning experiences.

Assignment two required learners to reflect on their experience during the five weeks of service-learning in the form of a reflective report derived from their daily reflective journals. The challenging part of the assignment was where learners were required to make connections between experience and theory (that which was learned in the programme), that is reflecting on experience through the use of what they had learnt through Modules 1 - 5.

The values that this module seeks to inculcate in learners are:

- Self as agent

- Respect for local knowledge

- Respect for others' perspectives

- Honesty and accountability

- Empathic sensitivity and awareness

- A critical attitude

- A sustainable intervention

- Participatory community development.

\section{Theoretical Frame Work}

Post colonialism problematizes the post-colonial endeavour. From a post-colonialist point of view neo colonialism is a planned and ongoing process through policy and aide to ensure the continuation of the old practice of dependency by the periphery which remains dependent on the centre (Altbatch 1995) and retainment of Western hegemony. Preece (2009), like many post colonialist theorists, (such as Young 2001, Altbach 1995) defines neo colonialism as representing:

ongoing, controlling behaviours by former colonizing countries and other superpowers that include monetary controls, influences over educational institutions, conditional aid and the spread of global capitalist economies (p. 20)

As such 'developing countries' continue to be exploited and therefore always remain in a perpetual 'developing' state.

Colonial experiences ensured that Africans were stripped of their identity but also were dehumanized and seen as subhuman (Chukwydi Eze, in Preece, 2005). It is for this reason that Afrocentricism "implores one to act upon the world to transform it, in support of social justice, social change, and social transformation." (Tolliver, 2002:7). For Chilisa and Preece (2005:43) transformation is promoted through the "documentation, description and analysis of the experiences of the colonized and their resistance to colonial rule". In other words it is about the generation of knowledge from an African point of view as well as developing spaces, language and opportunities for the formally colonised to be affirmed, heard in a culturally diverse context that links broader structural and cultural processes with the lived lives of local communities seeking explanations and answers from the oppressed point of view (Dube, 1999). 
Consequently Afrocentrism is characterized by the need to revive communal values, culture, customs, and traditions referred to broadly as 'collectivism' not only within countries and nations but across the African continent. Furthermore and critical to the Afrocentric view is the common assumption that there exist commonalities "in African peoples' culture(s) that should be interrogated and investigated to serve as the basis for Afrocentric unity..." (Dei,1994: 7).

The Afrocentric paradigm focuses on acknowledging our colonial history as Africans and its impact on us today in every sphere of life (Chilisa and Preece 2005, Mkabela 2005, Merriam and Ntseane 2008, Tolliver 2010 and Ntseane 2011). Afrocentric paradigm relates to African Confucianism and African humanism. African Confucianism centers on the belief that all human beings are teachable and improvable and African humanism is based on a belief in the positive potential of human nature and the need to provide space for this potential to develop (Merriam and Kim, 2008 and Pietersen, 2005). However, and most important, is its connection to post colonialism discourse, a discourse that emerged from the Third World countries (Young 2001), Non-Western perspectives (Marriam and Kim, 2008) or a tricontinental approach (Rukudwa and van Aarde (2007). Post-colonialist discourse is about the effects and impacts of colonialism on local people as an on-going experience during the post-colonial era in every aspect of life. It is about people seeking their identities and spaces to articulate their true freedoms.

Invariably, from an Afrocentric and post-colonial perspective learning opportunities and learning space should seek to inculcate indigenous knowledge systems, reaffirm and facilitate (re)humanistion by validation of African values as well as indigenous meaning making processes.

A growing literature reflecting both Western and African perspectives to meaning making continue to emerge and in support of the significance of communal learning (African perspective) or social learning (Western perspective). Fernwick and Tennant (2004) refer to this type of learning as practice-based community learning and learning as embodied co-emergent process. The view is supported by Brown, Collins and Duguid (1989) who are critical of decontextualized learning that result in the division between theory and practice. Again Wilson and Myers (2000) argue for the significance of the convergent of the individual and the social context in the learning process.

This is the understanding of learning process that informed how the Situated Supported Learning model (SSDL) the delivery mode of the programme was developed. The SSDL model is based on the social learning theory that learning happens in conversation with others (Maynard 2001 and Lave and Wenger 1991). From this situated cognition theory point of view learning can best take place in the context where it is likely to be applied. However, embedded in this understanding is the question - where is real knowledge located? The SSDL acknowledges the fact that knowledge might not always be located in Universities or books but in communities themselves. Situated learning therefore does not only enhance and contexualise learning for learners but creates spaces for learners to show case their local knowledge and agency. Rule (2004) refers to this context as a dialogic space, when all involved become teachers as well as learners.

From a SSDL model point of view learning in context is more than the formal learning $t$ but the informal learning as well. From a Western perspective there is a growing recognition of informal learning as a learning process. Proponents of informal learning strongly suggests that learning can be neither structured nor prescribed. It is based on activities, human interaction or human participation (Foley, 1993, Marsick \& Watkins, 1990, Livingstone, 2000, and Schugurensky, 2000). Foley (1993: 21) defines this learning as "embedded in, and incidental to, other activities."

Reflections on learners final reports based on their service learning experience in their final module in the programme all the elements discussed above emerged that is, poverty, ill health, child trafficking, learning with and from other and the role of informal learning. However the character of African Indigenous Learning (AIL) was also emerging strongly.

AlL is based on an African philosophy of humanism which states that a person is a person through others on Umuntu ngumuntu ngabantu (Letsaka, 2000, Ntuli, 2002, Swanson, 2007, Preece, 2009). Its philosophy is represented by the term Ubuntu amongst the Nguni languages, buthu in Pedi or Harrambee in Kiswahili. The emphasis in each language is on "connectedness, belongingness, identifications, well-being, love, compassion, peaceful co-existence with nature and among groups." (Sefa Dei, 2002:2) or a collective worldview, informed by spirituality and shared values (Ntseane, 2011). Ubuntu creates a central influence to indigenous 'ways of knowing and being' (Samson, 2007). Indeed the works of Merriam and Kim (2008), Chilisa and Preece (2005), Merriam and Ntseane (2008), Lekoko and Modise (2011) identify key characteristics of African indigenous learning as learning in community, learning as communal activity, lifelong, informal, holistic or spiritual.

\section{Methodology for Investigating Learner Experiences}

A qualitative research design was used, where an interpretivist paradigm was employed to enable the researcher to gain a descriptive understanding of the values, actions and concerns of the learners under study as well as to analyze their 
experiences as captured in their final reflective reports (Bertram and Christiansen, 2014 and Blanche, Durrheim and Painter, 2006).

\subsection{Sample}

Convenience sampling was used to select 2 reports from each of the eight countries (Bertram and Christiansen, 2014 and Blanche, Durrheim and Painter, 2006). Those selected were analyzed for basic descriptive data addressing the research questions. These were from the first phase of the programme.

A summary page was prepared from each student's report, capturing the basic descriptive data for their servicelearning project. In addition the reports were analysed for any learning that was highlighted. This analysis aimed to answer the following research questions:

1. What was the nature of the service-learning projects students chose to undertake in their communities?

a. What did the student actually do during their placement?

b. What kind of organization were they attached to?

c. What was the target community of that organization and the project?

2. What learning did the student report through the experience?

a. About themselves?

b. About the field of working with children at risk?

c. About working with/in the community?

While the learner's final reports were useful as primary sources for data it must be acknowledged that these reports were not designed as research instruments nor for research purposes; as a result there are limitations on the depth of data provided. Nevertheless final reports are the authentic learner's reflective spaces on real practical project presented in the first assignment of this module as a project proposal.

Deductive text data analysis was employed and categories of key characteristics of what African Indigenous Learning were developed from literature (Bertram and Christiansen, 2014).

\section{The findings and discussions}

This section presents the nature of the service-learning projects undertaken, processes of learning that took place as perceived by learners themselves and three other types of learning that emerged: learners about themselves as learners, the field of working in the area of vulnerable children and lastly working in communities.

\subsection{The nature of the service-learning projects undertaken.}

Learners undertook a diverse range of real community based projects across the continent, confronting the tangible realities of different communities. Below are three examples of such projects.

The Salvation Army is the host organisation in Malawi for X project learner. Her aim for her service learning project was to provide support to children rescued from trafficking and their families. In the five weeks she developed an inventory list of local community structures available in the area that could assist in providing support to rescued children. She further identified capacity needs for these structures and provided training to some of these community based structures.

Y project learner was hosted by a local NGO working with vulnerable children in Lesotho. His aim was to raise awareness and sensitise the community on the provisions of the new Children's and Welfare Act, 2011 of Lesotho. Y in the five weeks planned, organised and facilitated three workshops with different constituencies.

Z project learner had identified a need within a farming community in Zimbabwe to provide psycho social support for vulnerable children and their families living in the area. He also provided organisational support to the host organisation working in this community. He planned, organised and facilitated two workshops for the organisation on child counselling skills and evaluated these workshops

The eight samples selected as reflected by the three cases present different scenarios of the plight faced by the African continent as a consequence of Colonialism. The cases reflect a dehumanized and almost subhuman society. The programme through this module creates space for a cadre of practitioner to stand up to the challenge and reclaim the status of being human. 
The module design is such that it immerses learners in the centre of a community's realities. Learners identify a community problem and develop structured plans to confront it within an organisation so that the work started is sustained within that organisation but most importantly, that learners are supported by more experienced practitioners. Module 6 becomes the capstone of the entire programme since learners get an opportunity to practically implement the 'theoretical' work learnt in the programme. Furthermore learners get to realise and appreciate that local communities have in place local systems to deal with their local problems (Swanepoel and De Beer, 2011 and Davids, Theron and Mapunye, 2005). While the learner might initially think that $s /$ he has all the solutions $s /$ he soon realises that s/he has a lot of local knowledge to learn.

\subsection{The process of learning}

A text analysis of the learning process engaged by learners suggested that their reflections embraced strong connections to the African spirit of Ubuntu.

These are thematically presented here as: learning as communal activity, learning as a practice of caring and lastly learning as problem solving.

\subsubsection{Learning as communal activity}

We worked as a team and discussed everything in the programme and life in general. (Uganda)

We lived and studied like members of the same family. ( Zimbabwe)

We were like a family and helped with assignments. (Namibia)

My fellow learners were very helpful and contributed during the discussions. Each one contributed/shared their own experiences and that encouraged us to work as a team. (Malawi)

Participation and pulling together seem to have revived a sense of collectivism that is reflected as communal values, culture, customs, and traditions. Merriam and Ntseane define communal in terms of "awareness of others, promoting cooperation" (Merriam and Ntseane, 2008: 187).

\subsubsection{Learning as a practice of caring}

The practice of caring is reflected in the isizulu saying "izandla ziyagezana". Directly translated this means "hands wash each other' or 'you can never be human alone' (Mbigu \& Maree 1995, Mangaliso and Damane 2001). This analogy relates to the concept of ujaama initiated by Nyerere in Tanzania, Nkrumasim or African socialism by Nkruma in Ghana, Fanon in Algeria, Chinua Achebe in Nigeria, Ngugi wa Thiongo in Kenya and many others. Merriam and Ntseane (2008) connect the practice of caring with spirituality giving rise to the obligation to the community as reflected in the learners' reflections:

They prayed and counselled me when I lost my job and had many family problems. (Swaziland)

At the beginning of the course in Module 1 I decided to discontinue the programme because I found it difficult to share my time for studies but my fellow learners encouraged me and helped me make a study timetable. (Malawi)

They were generous and responded to my problems. (Tanzania)

When I was about to quit because of great stress they helped me with my work and motivated me. ( Lesotho)

When I was absent for a time they called to enquire how things were going and were available to help. (Namibia)

They loaned me money for transport so I could attend and not be absent. (Zambia)

\subsubsection{Learning as problem solving}

In presenting learning process as problem solving we are not suggesting that African indigenous learning is the sole locus for this kind of learning. Nevertheless, Zulu (2001) in his paper titled Critical Indigenous African Education and 
Knowledge, laments the fact that indigenous learning has over the past years been defined in simplistic terms with a focus on socialisation. However, African indigenous learning can also be about "self-learning...immediacy of application of learning" (Lekoko and Modise, 2010: 25). Here we show how learning is immediately applied to bring about change.

Child participation has become very big in my community. They fight for their rights and they even challenge the police about child protection. They had a march to the police station and demanded to be protected against criminal activities that happen around the community. (Uganda)

I was able to work with a particular community and I trained them on PSS. The community has managed to open a day care centre where they run a food programme which at the end of the day helps children to develop in many ways. (Zimbabwe)

Before I joined this programme there was a lot of abuse of children's rights in my community but after acquiring knowledge from the course I have tried to sensitise my community about children rights and there is now a reduction in abuse of children rights. (Uganda)

The learning reported and reflected above is also grounded in the notion of praxis. Freire defined praxis as "the action and reflection of people upon their world in order to transform it" (Freire:1972: 60). For Freire, praxis, is a critical element of dialogue. He argued that true dialogue couldn't exist unless those involved are engaged in critical thinking, perceiving reality as a process of transformation. Grundy (1987:77) defines praxis as "the act of reflecting, constructing or reconstructing the social world" or "Praxis is the form of action which is the expression of the emancipatory interest." In this programme learners were not only aware of their situation but module 6 created space for them to reflect and change that situation.

\subsection{The learnings reported by the learners}

Three types of learning emerged from the reports presented by learners: about themselves as learners; working in the area of vulnerable children; and lastly working in communities.

\subsubsection{About themselves as learners}

Learners clearly developed critical consciousness that pushed some to be community activists locating themselves within the Self-Reliant Participatory Development theory. Taba (1962) argues that the process of learning is about bringing about significant changes in the learners attitudes, behaviour and acquiring of new skills. An example of learning about the self is illustrated in the following quote.

was shy at first but have now gained experience and improved learning, have strength to change lives of the youth. Patience, determination... (Lesotho)

Through the service learning module learners also identified many instances of unintended learning that developed their sense of self-resilience, and self- agency as reflective practitioners.

I had determination when faced with challenges, flexibility, patience, self-discipline, organizational skills, empathy (Namibia)

Some of the identified skills and competences by learners included recognition that they could change and save lives of many in their communities. They further identified self-esteem as one of the key gains of participating in the module and the on-going development of skills such as listening, communication and facilitation skills.

\subsubsection{The field of working in the area of vulnerable children}

While all the learners had experience in working with vulnerable children, module 6 gave a safe space to try out new approaches as well as structure reflection. However the emotional aspect of this work remains the same.

Having skills and knowledge gives the caregivers confidence and enables them to care and support children feelings and emotions at different times. Being able to deal with own feelings of grief and loss also increases their capacity to 
help children and their families. It is important for the caregivers to have relationships with children if they are to help them. The caregiver should have qualities that will make the child trust them and feel free to have an attachment with them. (Zimbabwe)

Cultures and gender stereotypes were identified as major limitations in the work they were doing.

Different gender roles and responsibilities; children have little say in their lives (Tanzania)

Children in target groups are victims of child labour which exposes them to various risks while at work place. Children in the target group have a few opportunities for free expression of their opinions. (Uganda)

It was very difficult for the different genders to sit facing one another in counselling (Tanzania)

Learners demonstrated awareness of the challenges that communities face and how these make communities weak and vulnerable.

poverty and hunger affect both in traditional houses and modern ones (Lesotho)

Mtsiliza is vulnerable to adversities such as poverty, conflict, HIV \& AIDS, prostitution, theft and alcohol and drug abuse (Malawi)

They are powerless, isolated, poor and physically weak (Swaziland)

The types of learning that emerged from the learners create a picture of critical and reflective practitioners defining their learning within the context of local communities and being one with their communities, grounded in communal values informed by human interaction, interdependency, group solidarity or participation and localized learning. "Sitting next to Nellie" (Lekoko and Modise, 2011). It is "the learning taken for granted" (Hoppers, 2009: 11), or "just having a little chat." (Falk and Harrison, 2006).

\subsubsection{On local knowledge systems:}

Learning from the communities is important; using ideas and opinions from community ensures sustainability of the project; important to be adaptive; bigger is not always better (Zimbabwe)

...should work hand in hand with the community because they know their problems (Lesotho)

Community satisfaction important for successful development (Uganda)

Active participation was also reflected as:

Community should be active participants, should take responsibility for the school too, can't participate if not informed, use certain strategies, which need to be learnt, need to be empowered, not told what to do, need to decide on their own goals (Tanzania)

Community satisfaction important for successful development (Uganda)

adults are interested in participation in development work, culture/norms/values influence adversities, traditional leaders must be targeted when bringing change (Malawi)

The findings of the documented learner reflections illustrate learning processes that are arguably informed and shaped by African indigenous learning underpinned by Afrocentrism. Module 6 seems to have created a learning space that mediates between what learners learn in the programme with the space where that learning ought to be applied. This involved mediating the two in a cultural context, through a language familiar to both the learner and the community, most importantly in the interaction learning space where only local actors were involved without the physical presence of the outside actor and thereby creating a safe space informed by local knowledge, local language, local culture exploring and developing local agency.

This is in contradiction to what Sir Walter Moberly back in 1949 in his book The Crisis in the University defined as the role of University in society which was "a thought organization not a will organization and its aim is to understand 
rather than action" (Moberly, 1949:39). The findings echo one of the goals of Higher Education in South Africa which is to "promote and develop social responsibility and awareness amongst learners of the role of higher education in social and economic development through community service programs" (Department of Education 1997:10). Accordingly, the University of KwaZulu- Natal (UKZN) vision reflects this view: "A truly South African university that is academically excellent, innovative in research, critically engaged with society and demographically representative, redressing the disadvantages, inequities and imbalances of the past."

This study demonstrates how service learning is potentially a gateway into African Indigenous Learning underpinned by an Afrocentric paradigm. Through this process not only learners but the academia through learners work are reintroduced into local community forms of meaning making as well as indigenous knowledge systems. This raises the question: Does the academia value lessons from communities? The discourse of the practice of the Afrocentric paradigm is in the belief of human capacity and potential and the belief that I am because you are. This is a call for introspection onto practice and the aim of that practice within a globalising world. Does African higher education adopt the post-colonial stance and complete internationally? Do we adopt an Afrocentric stance acknowledge and address our challenges first? Or we can mediate the two? Whatever option reflection on these matters goes a long way in addressing issues of cognitive justice.

\section{Conclusion}

We believe that in the long run the special contribution to the world by Africa will be in this field of human relationship. The great powers of the world may have done wonders in giving the world an industrial and military look, but the great gift still has to come from Africa - giving the world a more human face. (Biko, 2009: 51).

This is the role of Higher Education in Africa. Giving the world a more human face by teaching towards the redevelopment of humanism Ubuntu, learning from indigenous communities about humanism Ubuntu, allowing concepts of humanism Ubuntu to inform curriculum development. This could be the gift Biko is talking about.

There are essentially two aspects presented in this paper: the promotion of afrocentric, indigenous learning practices and the opportunity to demonstrate the application and building of local knowledge through a situated learning module (service-learning); and the need for universities to make further spaces for such kinds of learning, the two-way exchange of information and knowledge generation. Indeed this is learning from teaching in communities.

\section{References}

Altbach, G.P. 1995. Education and colonialism, in Ashcroft, et al 1995: 452-456

Bertam, C. and Christiansen, I. 2014. Understanding research. Van Schaik Publisher.

Biko, S. 2009. Steve Biko I write what I like. Picado Africa Reprint.

Brill, B. 2001. Situated Cognition. In M. Orey (Ed). Emerging perspectives on learning, teaching and technology. Available Website: http://itstudio.coe.uga.educ/ebook/situatedcogntion.htm

Brown, J.S. Collins, A. and Duguid, P. 1989. Situated Cognition and the Culture of Learning - Educational Research. 18 (1), 32 - 42.

Blanche, M.T. Durrheim, K and Painter, D. 2006. Research in Practice: Applied Methods For The Social Sciences. UCT Press.

Brown, J.S. Collins, A. and Duguid, P. 1989. Situated Cognition and the Culture of Learning - Educational Research. 18 (1), 32 - 42.

Chilisa, B. and Preece, J. 2005. Research Methods for Adult Educators in Africa. Cape Town: UNESCO Institute for Education, Feldbrunnenstr.

Davids, I. Francois, T and Maphunye, K.J. 2005. Participatory Development in South Africa: A development Management Perspective. Pretoria: Van Schaik.

Dei, G.J. S. 2002. Spiritual Knowing and Transfomative Learning. The Research New York for New Approaches to Lifelong Learning (Unpublished: working paper)

Department of Education. (1997). Education White Paper 3: A programme for the Transformation of HigherEducation, Pretoria: Government Printers.

Diouf, W., Sheckley, B., Kehrhahn, M. 2000. Adult learning in a non-western context: The influence of culture in a Senegalese farming village. Adult Education Quarterly Nov 2000, Vol. 51 Issue 1; 32-44.

Dfid. 2000. Poverty elimination and the empowerment of women: Strategies for achieving international development target. London Dfid.

Dube, M.W. (1999). 'Searching for the lost needle: Double colonization and postcolonial African feminism' Studies in World Christianity, Vol.5, pp 213-229.

Edwards, R., Armstrong, P. \& Miller, N. 2001. Include me out: Critical readings of social exclusion, social inclusion and lifelong learning. Journal of Education Policy, 20(3): 417-428.

Falk, I. and Harrison, L. 2006. Community learning and social capital: "just having a little chat". Journal of vocational Education and Training, 50:4, 609-627. 
Fenwick, T and Tennant, M. (2004) Understanding Adult Learners in Foley, G. (Ed) (2004) Dimensions of Adult Learning. Maidenhead: Open University Press McGraw Hill Education.

Freire, P. (1975). Pedagogy of the Oppressed, Harmondsworth, UK: Penguin.

Foley, G. (1993). The Neibourhood House: site of struggle, site of learning. British Journal of Sociology of Education, Vol. 14, No1: 2137.

Grundy, S. 1987. Curriculum: Product or Praxis? The Falmer Press.

ISCED 1997. http://www.uis.unesco.org/Education/ISCEDMappings/Pages/default.aspx

Hoppers, C.A. 2009. Engaging Critically with Tradition, Culture, and Patriarchy through Lifelong Learning: What would Julius Nyere say? $6^{\text {Th }}$ Julius Nyerere Annual Lecture on Lifelong Learning Univertisty of the Western Cape $3^{\text {rd }}$ September 2009.

Jolly, L. And Radcliffe, D. 2000. Reflexivity and hegemony: Changing engineers. http://www.ascilite.org.au/aset-archives/confs/asetherdsa2000/procs/jolly2.html accessed on 201/03/18

Kalb, D., (2004). Time and contention in "the great globalisation debate". In Kalb,D., Pansters, W., and Siebers, H. (Ed). Globalisation and Development: Themes and Concepts in Current Research. Pp 9-48, London: Kluwer Academic Publishers.

Lave, J. and Wenger, C. 1991. Situated learning legitimate peripheral participation. Cambridge: University Cambridge Press.

Ledwith, M. 2001. Community work as critical pedagogy: Re-envisioning Freire and Gramsci. Community Development Journal Vol. 36. No. 3 July 2001, 171-182.

Lekoko, R. and Modise, O. 2011. An insight into an African perspective on lifelong learning: towards promoting functional compensatory programmes. International Joarnal of Lifelong Education. Vol. 30. No. 1. Pp 23- 35.

Letsaka, M. (2000). African philosophy and educational discourse. In African voices in education, ed. P. Higgs, N.C.G. Vakalisa, T.V. Mda, and N.T. Assie-Lumumba, 179-93. Lansdowne, PA: Juta and Co.

Litke, R.A. 2002. Do all Students get it?: Comparing Student Reflections to Course Performance. Michigan Journal of Community Service Learning. Spring 2002. Pp. 27-34.

Livingstone, D. 2001. Adults' informal learning: Definitions, findings, gaps and future research. WALL Working Paper No.21, 2001. Centre for the Study of Education and Work. Ontario Institute for Studies in Education of the University of Toronto.

Mlia, M,W. and Loubser, C.P. 2003. Emancipatory Indigenous Knowledge Systems: implications for environmental education in South Africa. South African Journal of Education. Vol. 23, No 4. Pp $276-280$.

Marsick, V. And Volpe, M. 1999. "The Nature of and Need for Informal Learning." In V.J. Marsick and M. Volpe (eds), Informal Learning on the Job, Advances in developing Human resources, No 3. San Francisco: Berret Koehler.

Maynard, T. 2001. The student teacher and the school community of practice: A consideration of 'learning as participation. Cambridge Journal of Education. Vol 31, No 1.

Merriam, S.B., Johnson-Bailey, J. Lee, M., Kee, Y. Ntseane, G and Muhamad, M. 2001. Power and positionality: negotiating insider/outsider status within and across cultures. International Journal of Lifelong Learning, 20:5, 405-416.

Merriam, S.B. and Ntseane, G. 2008. Transformational Learning in Botswana: How Culture Shapes the Process. Adult Education Quarterly 2008 58: 183.

Merriam, S.B. and Kim, Y. S. 2008. Non-Western Perspectives on Learning and Knowing. New Directions for Adult and Continuing Education no 119.

Mangaliso, M.P. \& Damane, M.B. 2001. Building competitive advantage from ubuntu: Management lessons from South Africa, Academy of Management Executive; Aug 2001, 15, (3), 23-35.

Mbigi, L. \& Maree, J. 1995. Ubuntu: the spirit of African transformation management, Randburg, SA: Knowledge Resources (Pty) Ltd.

Moberly, W. 1949. The Crisis in the University. London: SCM Press Ltd.

Nashon, S. Anderson, D. and Wright, H. 2007. Editorial Introduction African Ways of Knowing, Worldviews and Pedagogy. Journal of Contemporary Issues in Education.

Ntseane, P. G. 2011. Culturally Sensitive Transformtional Learning: Incorporating the Africentric Paradigm and African Feminism. Adult Education Quarterly 2011 61: 307.

Ntuli, P. 1999. The missing link between culture and education: Are we still chasing Gods that are not ours? In M. Makgoba (ed. Afrocan Renaissance (Cape Town: Mafube)

Preece, J. 2009. Lifelong Learning and Development A southern Perspective. Continuum International Publishing Group.

Schugurensky, D. 2000. The forms of informal learning: Towards a conceptualization of the field. WALL Working paper No 19, 2000.

Swanepoel, H. and De Beer, F. 2011. Community Development: Breaking the cycle of poverty. $5^{\text {th }}$ Ed. South Afrca Juta.

Wilson, B.B. and Myers, K.M. 2000. Situated Cognition in Theoretical and Practical Context. In D. Jonassen, and S. Land (Eds) NJ: Lawrence Erlbaum Associates.

Rule, P. 2004. Dialogic spaces: adult education projects and social engagement. International Journal of Lifelong Education, Vol. 23. No. 4 (July -August 2004), 319-334 A historical case study: the Tuition Project

Omar, S.M. 2012. Rething Development from a Postcolonial Perspective. Journal of Conflictology, Vol. 3. Issue 1 (May 2012 ), 42 - 48.

Taba,H.(1962). Curriculum Development: Theory and Practice. John Wiley, New York.

University of Natal, 2000. Strategic Initiatives Documents. University of Natal. http://www.nu.ac.za/strategic/.

Young, R. (2003). Postcolonialism: A very short introduction. New York: Oxford University Press.

Zulu, I. M. 2006. Critical Indigenous African Education and Knowledge. The Journal of Pan African Studies. Vol. 1, No. 3 (March 2006). Pp $32-48$. 